\title{
Technological forecast of bearing capacity and properties of contact connection of bimetallic hollow spheres under electromagnetic pulses action
}

\author{
Musii R. S. ${ }^{1}$, Melnyk N. B. ${ }^{1}$, Dmytruk V. A. ${ }^{1,2}$, Zhydyk U. V. ${ }^{1}$ \\ ${ }^{1}$ Lviv Polytechnic National University, \\ 12 S.Bandera Str., 79013, Lviv, Ukraine \\ ${ }^{2}$ Centre of Mathematical Modelling, \\ IAPMM of Ukrainian National Academy of Sciences, \\ 5 Dudayev Str., 79005, Lviv, Ukraine
}

(Received 30 September 2019; Accepted 5 January 2020)

\begin{abstract}
The initial boundary-value problem of thermomechanics for a hollow bimetallic sphere under the action of a non-stationary electromagnetic field is formulated. The azimuthal component of the magnetic field strength vector, the temperature, and the radial component of the displacement vector are chosen to be the determining functions. To find them, a technique has been developed to solve the corresponding contact problems of electrodynamics, thermal conductivity, and thermal elasticity. This technique uses a quadratic approximation of the distributions of all determining functions with respect to the radial coordinate in each component layer. With its help, the basic initial boundary-value problems for the determining functions are reduced to the Cauchy problems for their integral (total over the layers package) characteristics. The general solutions to these problems are obtained under a homogeneous non-stationary electromagnetic action. On this basis, the solutions to the problem for bodies under the action of an electromagnetic pulse are written. A computer analysis of thermoelastic behavior, bearing capacity, and preservation of the properties of the contact connection of the sphere is carried out depending on the pulse parameters.
\end{abstract}

Keywords: bimetallic hollow sphere, thermal state, bearing capacity, properties of contact connection, electromagnetic pulse.

2010 MSC: 74A10, 74B10

DOI: $10.23939 / \mathrm{mmc} 2020.01 .079$

\section{Introduction}

In modern mechanisms and devices piece-homogeneous electrically conductive structural elements are widely used, which are under conditions of multifactorial loads. One of such elements being especially often used in electromagnetic adapters, a hollow bimetallic sphere is that is exposed to a pulsed electromagnetic field action (EMF) $[1,2]$. The reliability of the mentioned devices depends on retaining the bearing capacity of this element [1].

In literature, the investigations of the thermal stress state and the bearing capacity of homogeneous electrically conductive bodies of canonical shape under the action of pulsed EMFs [3-6], of a bimetallic layer and a cylinder [7-9] under such an action are known. However, there is insufficiently studied the hollow bimetallic sphere.

In this paper, the initial boundary-value problem of thermomechanics for a hollow bimetallic sphere under the action of a pulsed EMF has been considered and a method for its solving has been suggested. The thermal stress state and bearing capacity of the considered sphere under the action of electromagnetic pulse (EMP) have been investigated. 


\section{Central symmetric problem of thermomechanics for a bimetallic sphere}

\subsection{Problem formulation}

A hollow bimetallic sphere with inner $r=r_{0}$ and outer $r=r_{2}$ radii is considered, which is referred to a spherical coordinate system $(r, \varphi, \theta)$ whose center $O$ coincides with the center of the sphere. The materials of the component layers of the sphere are homogeneous isotropic non-ferromagnetic, and their physico-mechanical characteristics are constant. The sphere is under the action of a non-stationary EMF, given by the values of the azimuthal component $H_{\varphi}^{(n)}$ of the vector of the magnetic field strength $\boldsymbol{H}^{(n)}=\left\{0 ; H_{\varphi}^{(n)} ; 0\right\}$ on its inner and outer surfaces, which are heat-insulated from the environment and free from force loading. On the surface $r=r_{1}$ of the contact of the component layers of the sphere, the conditions of ideal electromagnetic, thermal, and mechanical contacts are satisfied.

In this case, the centrally symmetric problem of thermomechanics, all the key-functions of the problem - the component $H_{\varphi}^{(n)}(r, t)$ of the vector $\boldsymbol{H}^{(n)}$, the temperature $T^{(n)}(r, t)$, and the non-zero radial component $u_{r}^{(n)}(r, t)$ of the displacement vector $\boldsymbol{u}^{(n)}=\left\{u_{r}^{(n)} ; 0 ; 0\right\}$ are functions of the radial coordinate $r$ and the time $t$.

The mathematical model for determining the thermal stress state of the sphere under the action of a pulsed EMF consists in the consistent determination of the parameters of the EMF, temperature, and the radial component of the displacement vector.

The non-stationary EMF, which is described by the vector $\boldsymbol{H}^{(n)}$, is determined from the Maxwell relations taking into account the given boundary and contact conditions. With the help of the found vector $\boldsymbol{H}^{(n)}$, we find the Joule heat $Q^{(n)}$ and the ponderomotive forces $\boldsymbol{F}^{(n)}$ in each $n$-th $(n=1,2)$ component layer.

The non-stationary temperature field $T^{(n)}$ under convective heat exchange with the environment and under the given contact conditions is determined by the equation of thermal conductivity, in which the Joule heat $Q^{(n)}$ is a volumetric source of heat.

By means of the found temperature $T^{(n)}$ and the ponderomotive force $\boldsymbol{F}^{(n)}$ from the equations of dynamic thermal elasticity under the given boundary and contact conditions for the sphere, we calculate the displacement vector $\boldsymbol{u}^{(n)}$ and the dynamic stress tensor $\hat{\sigma}^{(n)}$.

To assess the bearing capacity of the sphere, we find the intensities $\sigma_{i}^{(n)}$ of the total stresses $\sigma_{j j}^{(n)}=\sigma_{j j}^{(n) Q}+\sigma_{j j}^{(n) F}(j=r, \varphi, \theta)$ in $n$-th layer. We calculate them according to the formula $\sigma_{i}^{(n)}=$ $\sqrt{\left(3 I_{2}\left(\hat{\sigma}^{(n)}\right)-I_{1}^{2}\left(\hat{\sigma}^{(n)}\right)\right) / 2}[4]$ and compare their value with the elasticity limit $\sigma_{d}^{(n)}$ of the material of the $n$-th layer. Here $\sigma_{j j}^{(n) Q}$ and $\sigma_{j j}^{(n) F}$ are stresses caused by the Joule heat $Q^{(n)}$ and by the ponderomotive force $\boldsymbol{F}^{(n)}, I_{j}\left(\hat{\sigma}^{(n)}\right)(j=1,2)$ is j-th invariant of the stress tensor $\hat{\sigma}^{(n)}$.

To predict the bearing capacity and preserve the properties of the connector, we will proceed from the well-known Huber-Mises criterion [10] for homogeneous bodies. A bimetallic sphere retains its bearing capacity as a structural element if in its both layers the condition holds

$$
\sigma_{i}^{(n)}<\sigma_{d}^{(n)}
$$

The properties of the sphere under consideration as a structural element are retained if the stress intensities $\sigma_{i}^{(n) *}$ in the component layers on the contact interface do not exceed the value of the strength limit $\sigma_{M}$ of the contact of the layers. That is

$$
\sigma_{i}^{(n) *}<\sigma_{M}
$$

According to the mathematical model chosen, we consider sequentially the determination of EMF, temperature, and thermoelastic behavior of the bimetallic sphere. 


\subsection{Determination of EMP}

The azimuthal component $H_{\varphi}^{(n)}(r, t)$ of the vector $\boldsymbol{H}^{(n)}$ in each $n$-th component layer is determined from the equation [5]

$$
\frac{\partial^{2} H_{\varphi}^{(n)}}{\partial r^{2}}+\frac{2}{r} \frac{\partial H_{\varphi}^{(n)}}{\partial r}-\sigma_{n} \mu_{n} \frac{\partial H_{\varphi}^{(n)}}{\partial t}=0
$$

under the boundary conditions on the inner and outer surfaces of the sphere

$$
H_{\varphi}^{(1)}\left(r_{0}, t\right)=H_{\varphi}^{-}(t), \quad H_{\varphi}^{(2)}\left(r_{2}, t\right)=H_{\varphi}^{+}(t)
$$

and under the conditions of ideal electromagnetic contact on the surface of the contact of the layers of the sphere

$$
H_{\varphi}^{(1)}\left(r_{1}, t\right)=H_{\varphi}^{(2)}\left(r_{1}, t\right), \quad \frac{\partial H_{\varphi}^{(1)}\left(r_{1}, t\right)}{\partial r}+\frac{H_{\varphi}^{(1)}\left(r_{1}, t\right)}{r_{1}}=k_{\sigma}\left(\frac{\partial H_{\varphi}^{(2)}\left(r_{1}, t\right)}{\partial r}+\frac{H_{\varphi}^{(2)}\left(r_{1}, t\right)}{r_{1}}\right)
$$

as well as under the initial conditions $H_{\varphi}^{(n)}(r, 0)=0$. By means of the found function $H_{\varphi}^{(n)}(r, t)$, the specific density of the Joule heat $Q^{(n)}(r, t)$ and the ponderomotive force $\boldsymbol{F}^{(n)}=\left\{F_{r}^{(n)}(r, t) ; 0 ; 0\right\}$ are determined by the formula

$$
Q^{(n)}=\frac{1}{\sigma_{n}}\left(\frac{\partial H_{\varphi}^{(n)}}{\partial r}+\frac{H_{\varphi}^{(n)}}{r}\right)^{2}, \quad F_{r}^{(n)}=-\mu_{n}\left(\frac{\partial H_{\varphi}^{(n)}}{\partial r}+\frac{H_{\varphi}^{(n)}}{r}\right) H_{\varphi}^{(n)} .
$$

\subsection{Determination of the temperature field}

By means of the specific density of Joule heat $Q^{(n)}(r, t)$, we determine the temperature distribution $T^{(n)}(r, t)$ in each $n$-th layer of the sphere from the equation of heat conduction [5]

$$
\frac{\partial^{2} T^{(n)}}{\partial r^{2}}+\frac{2}{r} \frac{\partial T^{(n)}}{\partial r}-\frac{1}{\kappa_{n}} \frac{\partial T^{(n)}}{\partial t}=-\frac{Q^{(n)}}{\lambda_{n}}
$$

under the boundary conditions of thermal insulation on the inner and outer surfaces of the sphere

$$
\frac{\partial T^{(1)}\left(r_{0}, t\right)}{\partial r}=0, \quad \frac{\partial T^{(2)}\left(r_{2}, t\right)}{\partial r}=0
$$

and under the conditions of ideal thermal contact at the contact interface of its component layers

$$
T^{(1)}\left(r_{1}, t\right)=T^{(2)}\left(r_{1}, t\right), \quad \frac{\partial T^{(1)}\left(r_{1}, t\right)}{\partial r}=k_{\lambda} \frac{\partial T^{(2)}\left(r_{1}, t\right)}{\partial r}
$$

and under the initial conditions $T^{(n)}(r, 0)=0$.

\subsection{Determination of the stress state}

To determine nonzero components: radial $\sigma_{r r}^{(n)}$, azimuthal $\sigma_{\varphi \varphi}^{(n)}$, and meridional $\sigma_{\theta \theta}^{(n)}$ components of the tensor of dynamic stresses $\hat{\sigma}^{(n)}(r, t)$ in each $n$-th layer of the sphere, we choose as a base the system of equations of the centrally symmetric thermoelasticity problem in terms of displacements [5]. Then the radial component $u_{r}^{(n)}(r, t)$ of the displacement vector in the $n$-th layer of the sphere is determined from the equation [5]

$$
\frac{\partial^{2} u_{r}^{(n)}}{\partial r^{2}}+\frac{2}{r} \frac{\partial u_{r}^{(n)}}{\partial r}-\frac{2}{r^{2}} u_{r}^{(n)}-\frac{1}{c_{n}^{2}} \frac{\partial^{2} u_{r}^{(n)}}{\partial t^{2}}=\alpha_{n} \frac{1+\nu_{n}}{1-\nu_{n}} \frac{\partial T^{(n)}}{\partial r}-\frac{\left(1+\nu_{n}\right)\left(1-2 \nu_{n}\right)}{E_{n}\left(1-\nu_{n}\right)} F_{r}^{(n)}
$$

Mathematical Modeling and Computing, Vol.7, No. 1, pp. 79-87 (2020) 
under the boundary conditions on the inner and outer surfaces of the ball

$$
\begin{aligned}
& \frac{\partial u_{r}^{(1)}\left(r_{0}, t\right)}{\partial r}+\frac{\nu_{1}}{1-\nu_{1}} \frac{2}{r_{0}} u_{r}^{(1)}\left(r_{0}, t\right)=\alpha_{1} \frac{1+\nu_{1}}{1-\nu_{1}} T^{(1)}\left(r_{0}, t\right), \\
& \frac{\partial u_{r}^{(2)}\left(r_{2}, t\right)}{\partial r}+\frac{\nu_{2}}{1-\nu_{2}} \frac{2}{r_{2}} u_{r}^{(2)}\left(r_{2}, t\right)=\alpha_{2} \frac{1+\nu_{2}}{1-\nu_{2}} T^{(2)}\left(r_{2}, t\right),
\end{aligned}
$$

under the conditions of ideal mechanical contact on the contact interface of its layers

$$
\begin{aligned}
u_{r}^{(1)}\left(r_{1}, t\right) & =u^{(2)}\left(r_{1}, t\right) \\
\left(1-\nu_{1}\right) \frac{\partial u_{r}^{(1)}\left(r_{1}, t\right)}{\partial r} & +\nu_{1} \frac{2}{r_{1}} u_{r}^{(1)}\left(r_{1}, t\right)-\alpha_{1}\left(1+\nu_{1}\right) T^{(1)}\left(r_{1}, t\right) \\
& =k_{E}\left[\left(1-\nu_{2}\right) \frac{\partial u_{r}^{(2)}\left(r_{1}, t\right)}{\partial r}+\nu_{1} \frac{2}{r_{1}} u_{r}^{(2)}\left(r_{1}, t\right)-\alpha_{2}\left(1+\nu_{2}\right) T^{(2)}\left(r_{1}, t\right)\right],
\end{aligned}
$$

and under the initial condition $u_{r}^{(n)}(r, 0)=0, \frac{\partial u_{r}^{(n)}(r, 0)}{\partial r}=0$.

By means of the found component $u_{r}^{(n)}(r, t)$ of the displacement vector $\boldsymbol{u}^{(n)}$, we determine the components $\sigma_{j j}^{(n)}$ of the stress tensor $\hat{\sigma}^{(n)}$ in the $n$-th layer of the sphere by the formulae [10]

$$
\begin{aligned}
& \sigma_{r r}^{(n)}=\frac{E_{n}}{\left(1+\nu_{n}\right)\left(1-2 \nu_{n}\right)}\left[\left(1-\nu_{n}\right) \frac{\partial u_{r}^{(n)}}{\partial r}+\nu_{n} \frac{2}{r} u_{r}^{(n)}-\alpha_{n}\left(1+\nu_{n}\right) T^{(n)}\right] \\
& \sigma_{\varphi \varphi}^{(n)}=\sigma_{\theta \theta}^{(n)}=\frac{E_{n}}{\left(1+\nu_{n}\right)\left(1-2 \nu_{n}\right)}\left[\nu_{n} \frac{\partial u_{r}^{(n)}}{\partial r}+\frac{u_{r}^{(n)}}{r}-\alpha_{n}\left(1+\nu_{n}\right) T^{(n)}\right]
\end{aligned}
$$

By means of the known total displacements $u_{r}^{(n)}$ and stresses $\sigma_{j j}^{(n)}$, we calculate the intensities of the stresses $\sigma_{i}^{(n)}$ in the $n$-th layer of the sphere by the formula

$$
\sigma_{i}^{(n)}=\left|\sigma_{r r}^{(n)}-\sigma_{\varphi \varphi}^{(n)}\right|
$$

Based on the found intensities $\sigma_{i}^{(n)}$, we analyze the bearing capacity and the retention of properties of the contact joint of the sphere using the relationships (1), (2).

\section{The technique of the initial boundary-value problems solutions construction}

To solve the formulated initial-boundary value problems of electrodynamics, thermal conductivity, and thermal elasticity with respect to determining functions $\Phi^{(n)}=\left\{H_{\varphi}^{(n)}(r, t), T^{(n)}(r, t), u_{r}^{(n)}(r, t)\right\}$, we approximate their distributions with respect to the radial variable $r$ in the $n$-th layer of the sphere by the quadratic polynomials $[7,8]$

$$
\Phi^{(n)}(r, t)=\sum_{i=0}^{2} a_{i}^{\Phi(n)}(t) r^{i}
$$

The coefficients $a_{i}^{\Phi(n)}(t)$ of the approximation polynomials (6) we determine by the integral (total over the packet of layers) characteristics $\Phi_{s}(t)$ of the key-functions $\Phi^{(n)}(r, t)$

$$
\Phi_{s}(t)=\sum_{n=1}^{2} \int_{r_{n-1}}^{r_{n}} \Phi^{(n)}(r, t) r^{s+l} d \gamma, \quad s=1,2
$$


and by the boundary conditions on the inner and outer surfaces and on the contact interface of the layers. Here $l=0$ to determine $H_{\varphi}^{(n)}(r, t), T^{(n)}(r, t)$ and $l=1$ to determine $u_{r}^{(n)}(r, t)$. To find the integral characteristics $\Phi_{s}(t)$, the initial equations (3)-(5) we integrate according to (9) taking into account the expressions (8). As a result, the initial boundary-value problems for the key-functions are reduced to the corresponding Cauchy problems for the integral characteristics of these functions, which are described by the systems of equations

$$
\begin{aligned}
& \left\{\begin{array}{l}
\frac{d H_{1}(t)}{d t}-d_{1} H_{1}(t)-d_{2} H_{2}(t)=d_{3} H_{j}^{-}(t)+d_{4} H_{j}^{+}(t), \\
\frac{d H_{2}(t)}{d t}-d_{5} H_{1}(t)-d_{6} H_{2}(t)=d_{7} H_{j}^{-}(t)+d_{8} H_{j}^{+}(t),
\end{array}\right. \\
& \left\{\begin{array}{l}
\frac{d T_{1}}{d t}+d_{1}^{T} T_{1}+d_{2}^{T} T_{2}=Q_{1}^{*}(t) \\
\frac{d T_{2}}{d t}+d_{3}^{T} T_{1}+d_{4}^{T} T_{2}=Q_{2}^{*}(t)
\end{array}\right. \\
& \left\{\begin{array}{l}
\frac{d^{2} u_{r 1}}{d t^{2}}-d_{1}^{*} u_{r 1}-d_{2}^{*} u_{r 2}=W_{1}^{*}(t), \\
\frac{d^{2} u_{r 2}}{d t^{2}}-d_{6}^{*} u_{r 1}-d_{7}^{*} u_{r 2}=W_{2}^{*}(t) .
\end{array}\right.
\end{aligned}
$$

The Cauchy problems (10) are solved with the given initial conditions for the key-functions, the initial conditions that are written using the relation (9) for their integral characteristics of these functions.

Here, the coefficients $d_{1 \div 8}, d_{1 \div 4}^{T}, d_{1 \div 4}^{*}$ are determined by the geometric parameters and the physical and mechanical characteristics of the component layers of the sphere, $Q_{s}^{*}(t), W_{s}^{*}(t)(s=1,2)$ are the right sides of the equations (2) and (3) integrated in accordance with (7) taking into account the expressions $T^{(n)}$ and $F_{r}^{(n)}$ on the surface of the connection of the layers.

The solutions of the Cauchy problems (10) using the Laplace transform with respect to the time variable are written in the form of convolutions of the given boundary conditions and the homogeneous solutions of the Cauchy problems. We obtain the expressions of the component $H_{\varphi}^{(n)}(r, t)$

$$
\begin{aligned}
H_{\varphi}^{(n)}(r, t)=\sum_{i=0}^{2}\left\{\sum_{s=1}^{2} a_{i s}^{(n)} \sum_{k=1}^{2} \int_{0}^{t}\left[A_{s 1}(k) H_{j}^{-}(\tau)+A_{s 2}(k) H_{j}^{+}(\tau)\right]\right. & e^{p_{k}(t-\tau)} d \tau \\
& \left.+a_{i 3}^{(n)} H_{j}^{-}(t)+a_{i 4}^{(n)} H_{j}^{+}(t)\right\} r^{i}
\end{aligned}
$$

temperature $T^{(n)}(r, t)$ and components $u_{r}^{(n) Q}(r, t)$ and $u_{r}^{(n) F}(r, t)$ of the radial component $u_{r}^{(n)}(r, t)$ of the displacement vector $\boldsymbol{u}^{(n)}$

$$
\begin{gathered}
T^{(n)}(r, t)=\sum_{k=0}^{2} \sum_{s=1}^{2}\left(b_{k s}^{(n)} \sum_{m=1}^{2} \int_{0}^{t}\left[B_{s 1}(m) W_{1}^{Q}(\tau)+B_{s 2}(m) W_{2}^{Q}(\tau)\right] e^{p_{m}(t-\tau)} d \tau\right) r^{k}, \\
u_{r}^{(n)}(r, t)=\sum_{i=0}^{2}\left\{\sum_{s=1}^{2} c_{i s}^{(n)} \sum_{k=1}^{4} \int_{0}^{t}\left[R_{s 1}^{*}(k) W_{1}^{*}(\tau)+R_{s 2}^{*}(k) W_{2}^{*}(\tau)\right] e^{p_{k}(t-\tau)} d \tau\right\} r^{i} .
\end{gathered}
$$

By the known expressions (13) of the functions $u_{r}^{(n)}(r, t)$, from the relationships (6)-(7) we determine the radial $\sigma_{r r}^{(n)}$, azimuthal $\sigma_{\varphi \varphi}^{(n)}$, and meridional $\sigma_{\theta \theta}^{(n)}$ components of the stress tensor and the intensity of stresses $\sigma_{i}^{(n)}$. 


\section{Solutions of the problem under the action of electromagnetic pulse}

The action of EMP is mathematically described by the function $H_{\varphi}^{ \pm}(t)$ in the form [3]

$$
H_{\varphi}^{ \pm}(t)=k_{0} H_{0}\left(e^{-\beta_{1} t}-e^{-\beta_{2} t}\right) .
$$

Here $k_{0}$ is the normalization factor, $\beta_{1}$ and $\beta_{2}$ are the parameters that characterize the times of the front of growth $t_{i n e r}$ and of the front of decline $t_{d e k r}$, respectively, of the EMP of the $t_{i}$ duration, $H_{0}$ is the maximal value of the magnetic field strength of the pulse.

Substituting the expression (14) into the formulae (11)-(13), we write the solutions of the problem of thermomechanics for the considered sphere under the action of EMP. We obtain the expressions

$$
H_{\varphi}^{(n)}(r, t)=\frac{k_{0} H_{0}}{2} \sum_{i=0}^{2}\left(e^{-\beta_{1} t} B_{i 1}^{(n)}+e^{-\beta_{2} t} B_{i 2}^{(n)}+e^{p_{1} t} B_{i 3}^{(n)}+e^{p_{2} t} B_{i 4}^{(n)}\right) r^{i}
$$

of the component $H_{\varphi}^{(n)}(r, t)$,

$$
\begin{aligned}
& Q^{(n)}(r, t)=\frac{1}{\sigma_{n}} \frac{k_{0}^{2} H_{0}^{2}}{4} \sum_{i=1}^{2} \sum_{j=1}^{2}(i+1)(j+1) \sum_{l=1}^{20} C_{i j l}^{(n)} e^{\alpha_{l} t} r^{i+j-2}, \\
& F_{r}^{(n)}(r, t)=-\mu_{n} \frac{k_{0}^{2} H_{0}^{2}}{4} \sum_{i=1}^{2} \sum_{j=1}^{2}(i+1) \sum_{l=1}^{20} C_{i j l}^{(n)} e^{\alpha_{l} t} r^{i+j-1}
\end{aligned}
$$

of the specific densities of Joule heat and ponderomotive forces

$$
T^{(n)}(r, t)=\frac{k_{0}^{2} H_{0}^{2}}{4} \sum_{p=0}^{2} \sum_{m=1}^{2} \sum_{i=1}^{2} \sum_{j=1}^{2}(i+1)(j+1) \sum_{l=1}^{20} M_{i j l m}^{(n)} \frac{e^{p_{m} t}-e^{\alpha_{l} t}}{p_{m}-\alpha_{l}} r^{p}
$$

of the temperature $T^{(n)}(r, t)$,

$$
\begin{aligned}
& u_{r}^{(n) Q}(r, t)=\sum_{\alpha=0}^{2}\left[c_{\alpha 1}^{(n) Q} u_{r 1}^{Q}(t)+c_{\alpha 2}^{(n) Q} u_{r 2}^{Q}(t)+c_{\alpha 3}^{(n) Q} T^{(1)}\left(r_{0}, t\right)+c_{\alpha 4}^{(n) Q} T^{(2)}\left(r_{2}, t\right)+c_{\alpha 5}^{(n) Q} N_{0}^{Q}\left(r_{1}, t\right)\right] r^{\alpha}, \\
& u_{r}^{(n) F}(r, t)=\sum_{\alpha=0}^{2}\left[c_{\alpha 1}^{(n) F} u_{r 1}^{F}(t)+c_{\alpha 2}^{(n) F} u_{r 2}^{F}(t)\right] r^{\alpha}
\end{aligned}
$$

of the components $u_{r}^{(n) Q}(r, t)$ and $u_{r}^{(n) F}(r, t)$ of the radial displacements. Here

$$
\begin{aligned}
u_{r s}^{Q}(t)= & \frac{k_{0}^{2} H_{0}^{2}}{4} \sum_{\beta=1}^{4} \sum_{p=0}^{2} \sum_{m=1}^{2} \sum_{i=1}^{2} \sum_{j=1}^{2}(i+1)(j+1) \sum_{l=1}^{20} \frac{1}{p_{m}-\alpha_{l}}\left(\frac{e^{p_{m} t}-e^{p_{\beta} t}}{p_{m}-p_{\beta}}-\frac{e^{\alpha_{l} t}-e^{p_{\beta} t}}{\alpha_{l}-p_{\beta}}\right) \\
\times & \left\{R_{s \beta 1}^{Q}\left[d_{3}^{Q} M_{i j l m}^{(1)} r_{0}^{p}+d_{4}^{Q} M_{i j l m}^{(2)} r_{2}^{p}+d_{5}^{Q} M_{i j l m}^{(1)} K_{\alpha E} r_{1}^{p}-p\left(g_{p 11} M_{i j l m}^{(1)}+g_{p 12} M_{i j l m}^{(2)}\right)\right]\right. \\
& \left.+R_{s \beta 2}^{Q}\left[d_{8}^{Q} M_{i j l m}^{(1)} r_{0}^{p}+d_{9}^{Q} M_{i j l m}^{(2)} r_{2}^{p}+d_{10}^{Q} M_{i j l m}^{(1)} K_{\alpha E} r_{1}^{p}-p\left(g_{p 21} M_{i j l m}^{(1)}+g_{p 22} M_{i j l m}^{(2)}\right)\right]\right\}, \\
u_{r s}^{F}(t)= & -\frac{k_{0}^{2} H_{0}^{2}}{4} \sum_{\beta=1}^{4} \sum_{i=1}^{2} \sum_{j=1}^{2}(i+1) \sum_{l=1}^{20} \frac{e^{\alpha_{l} t}-e^{p_{\beta} t}}{\alpha_{l}-p_{\beta}} \sum_{m=1}^{2} \sum_{p=1}^{2} R_{s \beta m}^{F} \frac{\mu_{p}}{\rho_{p}} q_{m p} C_{i j l}^{(p)}, \\
N_{0}^{Q}\left(r_{1}, t\right)= & K_{\alpha E} T^{(1)}\left(r_{1}, t\right),
\end{aligned}
$$

$s=1,2, p_{1}, p_{2}, p_{m}, p_{\beta}$ are the roots of the corresponding characteristic equations, the coefficients $B_{i j}^{(n)}$, $C_{i j l}^{(n)}, M_{i j l m}^{(n)}, N_{s i j l}, B_{s j m}, P_{s \alpha q}, R_{s \beta k}^{Q}, R_{s \beta k}^{F}, g_{p s}, f_{s i j}, \gamma_{s}, K_{\alpha E}, c_{0 f}^{(n)}, b_{i j}^{(n)}, c_{m s}^{(n) F}$ are given in terms of geometric and physico-mechanical parameters of the sphere. 


\section{Numerical experiments}

We have analyzed the thermal stress state and bearing capacity of a bimetallic sphere with the radii of surfaces $\mathrm{r}_{0}=8 \mathrm{~mm}, r_{1}=9 \mathrm{~mm}, r_{2}=10 \mathrm{~mm}$, whose component layers are made of stainless steel and copper. The EMP characteristics are the following: $t_{i}=10^{-4} \mathrm{~s}, 10^{-3} \mathrm{~s}, \beta_{1}=6.9 / t_{i}, \beta_{2}=2 \beta_{1}, k_{0}=4$, for the steel layer $\sigma_{d}=300 \mathrm{MPa}$ and for the copper layer $\sigma_{d}=70 \mathrm{MPa}$ [3].

In Figs. 1-3, the time-variation of the radial component $\sigma_{r r}^{(n)}$ and azimuthal component $\sigma_{\phi \varphi}^{(n)}$ of stresses and stress intensities $\sigma_{i}^{(n)}$ in the steel (1) and copper (2) of the sphere on the contact interface are shown.

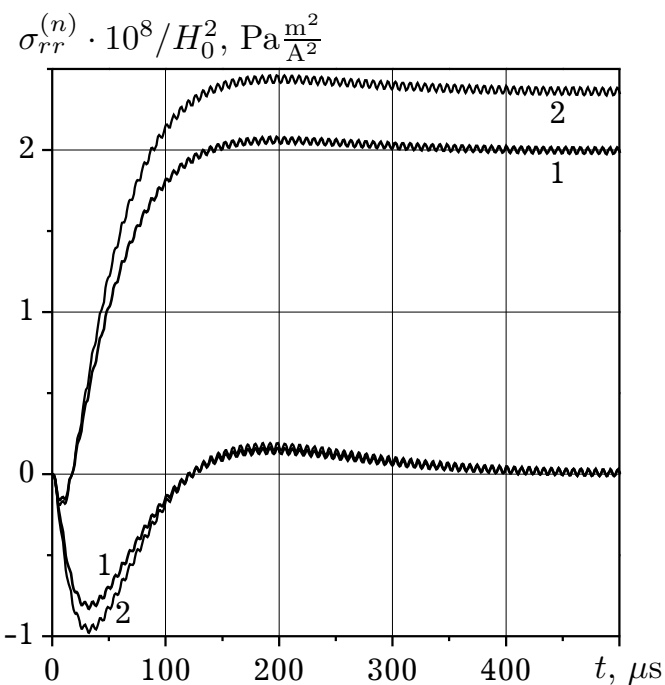

Fig. 1. Time-variation of radial stresses.

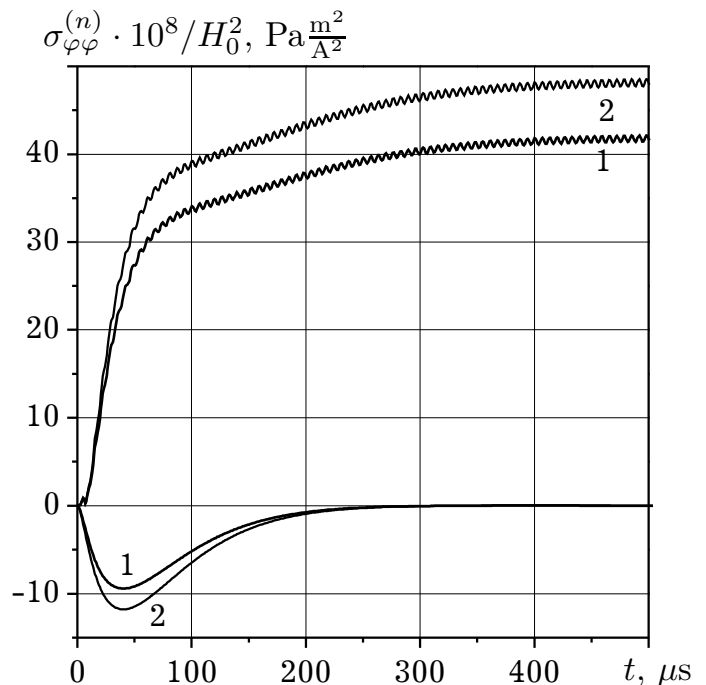

Fig. 2. Time-variation of azimuthal stresses.
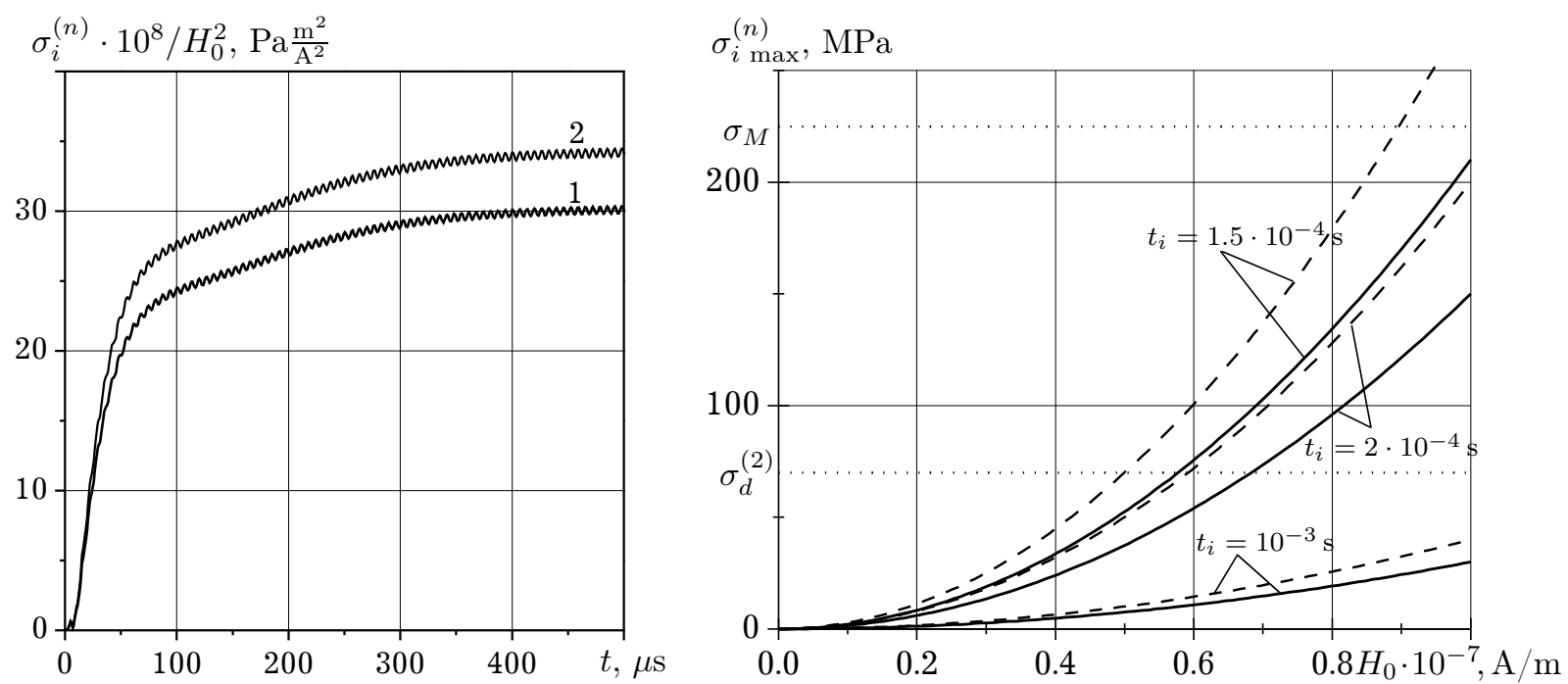

Fig. 3. Time-variation of intensities of stresses.

Fig. 4. The dependence of the maximal values of stress intensities on the value of $H_{0}$.

In Fig. 4, the dependences of the maximal values of the intensities of the stresses $\sigma_{i}^{(n) \max }$ in the $n$-th layer on the value of $H_{0}$ for different EMP durations are shown.

It is found that the bearing capacity of the considered sphere is lost when $t_{i} \leqslant 1.5 \cdot 10^{-4} \mathrm{~s}$. Accordingly, the properties of the contact connection are lost when $t_{i} \leqslant 1.5 \cdot 10^{-4} \mathrm{~s}$. 


\section{Conclusions}

On the basis of the suggested method, we found the general solutions of the constituent problems of electrodynamics, thermal conductivity, and thermal elasticity. In these solutions, all given boundary conditions on the inner and outer surfaces of the hollow sphere are strongly satisfied, as well as those on the interface of the connection of its layers. The initial boundary-value problems for the determining functions are reduced to the Cauchy problems for their integral characteristics. The solutions of these problems for bodies under the homogeneous non-stationary electromagnetic action have been found by using the Laplace transform as a convolution of functions describing the given boundary conditions and homogeneous solutions. The solutions to this problem have been written and numerically analyzed under the EMP action.

The rules of the thermomechanical behavior of the considered sphere and the limit values of the EMP parameters, provide exceeding of which the sphere loses its bearing capacity, are revealed.

[1] Matthews F., Rawlings R. Composite materials: engineering and science. London, Chapman \& Hall. 20-46 (1994).

[2] Shneerson G., Dolotenko M., Krivosheev S. Strong and Superstrong Pulsed Magnetic Fields Generation. De Gruyter (2010).

[3] Herlach F. Pulsed Magnets. Rep. Prog. Phys. 62 (6), 859-920 (1999).

[4] Podstrigach Ya. S., Burak Ya. I., Gachkevich A. R., Chernyavskaya L. V. Thermoelasticity of Electrically Conductive Bodies. Kiev, Naukova Dumka. 17-33 (1977), (in Russian).

[5] Musii R., Melnyk N., Dmytruk V. Thermoelastic processes analyzer for piecewise homogeneous conductive structures subjected to pulsed electromagnetic action. Journal of Thermal Stresses. 41 (9), 1125-1135 (2018).

[6] Motovilovets I. A., Kozlov V. I. Mekhanika svyazannykh poley v elementakh konstruktsiy. T.1: Termouprugost. Kiev, Naukova Dumka. 57-123 (1987), (in Russian).

[7] Podstrigach Ya. S., Koljano Ju. M. Generalized thermomechanics. Kiev, Naukova Dumka. 277-291 (1976), (in Russian).

[8] Singh S., Jain P. K., Rizwan-uddin. Analytical Solution for Three-Dimensional, Unsteady Heat Conduction in a Multilayer Sphere. J. Heat Trans. 138 (10), 101301 (2016).

[9] Musii R., Melnyk N., Dmytruk V. Investigation of properties of contact connector of bimetallic hollow cylinder under the influence of electromagnetic pulse. Mathematical Modeling and Computing. 5 (2), 193-200 (2018).

[10] Lurie A. I. Theory of Elasticity. Berlin, Springer-Verlag (2005). 


\title{
Прогнозування несучої здатності і властивостей контактного з'єднання біметалевих порожнистих куль за дії електромагнітних імпульсів
}

\author{
Мусій Р. С. ${ }^{1}$, Мельник Н. Б. ${ }^{1}$, Дмитрук В. А. ${ }^{1,2}$, Жидик У. В. ${ }^{1}$ \\ ${ }^{1}$ Начіональний університет "Лъвівська політехніка", \\ вул. С. Бандери, 12, Лъвів, 79013, Україна \\ ${ }^{2}$ Центр математичного моделювання
}

Інституту прикладних проблем механіки і математики ім. Я. С. Підстригача НАН Украӥни, вул. Д. Дудаєва, 15, Львів, 79005, Україна

\begin{abstract}
Сформульовано початково-крайову задачу термомеханіки для порожнистої біметалевої кулі за дії нестаціонарного електромагнітного поля. За визначальні функції вибрано азимутальну компоненту вектора напруженості магнітного поля, температуру та радіальну компоненту вектора переміщень. Для їх знаходження розвинуто методику розв'язування відповідних контактних задач електродинаміки, теплопровідності і термопружності. Ця методика використовує квадратичну апроксимацію розподілів всіх визначальних функцій за радіальною координатою в кожному складовому шарі. 3 її допомогою вихідні початково-крайові задачі на визначальні функції зведено до задач Коші на їх інтегральні (сумарні по пакету шарів) характеристики. Отримано загальні розв'язки цих задач за однорідної нестаціонарної електромагнітної дії. На їх основі записано розв'язки задачі за дії електромагнітного імпульсу. Проведено комп'ютерний аналіз термопружної поведінки, несучої здатності та збереження властивостей контактного з'єднання кулі залежно від параметрів імпульсу.
\end{abstract}

Ключові слова: біметалева порожниста куля, термонапружений стан, несуча здатність, властивості контактного з'єднання, електромагнітний імпульс. 